\title{
Ultra high frequency induction welding of powder metal compacts
}

\author{
Uğur Çavdar $^{\mathrm{a}, \bowtie}$, Ibrahim Gülșahin ${ }^{\mathrm{b}}$ \\ ${ }^{a}$ Celal Bayar University, Vocational School, Department of Machinery, Turgutlu Campus, 45400 Manisa, Turkey \\ ${ }^{\mathrm{b}}$ Celal Bayar University, Mechanical Engineering Department, Muradiye Campus Manisa, Turkey \\ Corresponding author: ugur.cavdar@cbu.edu.tr
}

Submitted: 30 January 2014; Accepted: 23 February 2014

\begin{abstract}
The application of the iron based Powder Metal (PM) compacts in Ultra High Frequency Induction Welding (UHFIW) were reviewed. These PM compacts are used to produce cogs. This study investigates the methods of joining PM materials enforceability with UHFIW in the industry application. Maximum stress and maximum strain of welded PM compacts were determined by three point bending and strength tests. Microhardness and microstructure of induction welded compacts were determined.
\end{abstract}

KEYWORDS: Iron; Powder metal compacts; Induction; Ultra high frequency induction welding; Welding

Citation / Cómo citar este artículo: Çavdar, U., Gülșahin, I. (2014) "Ultra high frequency induction welding of powder metal compacts". Rev. Metal. 50(2): e016. doi: http://dx.doi.org/10.3989/revmetalm.016.

RESUMEN: Soldadura por inducción de ultra alta frecuencia de polvos de metal compactados. Se ha realizado un estudio de la aplicación de polvos de metal (PM) de base hierro compactados por soldadura por inducción de ultra alta frecuencia (UHFIW). Estos polvos de metal compactados se utilizan para producir engranajes. Este estudio investiga los métodos de unión de los materiales de PM con UHFIW en su aplicación en la industria. La máxima tensión y la máxima deformación de los polvos de metal compactados soldados fueron determinadas por flexión en tres puntos y prueba de resistencia. Se determinó la microdureza y la microestructura de los polvos compactados por soldadura por inducción.

PALABRAS CLAVES: Hierro; Inducción; Polvos de metal compactados; Soldadura; Soldadura por inducción de ultra alta frecuencia

Copyright: $₫ 2014$ CSIC. This is an open-access article distributed under the terms of the Creative Commons AttributionNon Commercial (by-nc) Spain 3.0 License.

\section{INTRODUCTION}

In the commercial applications of PM, there are always other competitive technologies. The reasons for using powder metal technology are good tolerances, low cost, net shaping, high production rates, and controlled properties (German, 1994). PM has major strengths in the production of large quantities of complex geometries to precise specifications (German, 1994). In iron powder metallurgy, common sintering conditions are: 15-60 minutes at $1120-1150{ }^{\circ} \mathrm{C}$ (German, 1996). Particles of commercial iron powders for structural parts are usually $\leq 150 \mu \mathrm{m}$. Iron-copper-carbon alloys illustrate the unique properties possible by PM (German, 1996). Copper and graphite (carbon) are mixed with iron and during sintering the copper forms a liquid phase. This gives the compacts better strength. Iron based compacts are used in lots of industry applications. Worldwide, the biggest market for PM compacts is 
the automotive industry. In this industry, many parts are produce by iron based compacts, from gears to connecting rods and because PM compacts are iron based they can be welded by ultra high frequency induction.

Powder metallurgical industry is very interested in spreading its applications and improves the quality of the PM products. Many different types of models have been used to represent the mechanical behavior of these materials; however, nowadays, most of the groups working in this field admit that metallic powders and green compacts have to be considered as granular materials. Plasticity models specially defined for geological materials are being applied on metallic aggregates (Riera and Prado, 2006).

For necessary to increase the scientific and technical level of economy throughout the world, (Kuznetsov and Zernin, 2012) reviewed the application of nanotechnologies and nanomaterials in welding production. They reported electroslag, laser, and diffusion bonding results in efficient bonding of the materials with special properties and the technical-economic parameters of the process using the materials containing nanostructured components must be determined (Kuznetsov and Zernin, 2012).

Shulyak et al., (2011) described an experience of conducting local heat treatment of welded largesized pressurized cylinders using induction heating by medium frequency current of $2500 \mathrm{~Hz}$ (Shulyak et al., 2011). They reported that in local heat treatment of the welded joints in the large pressure vessels using induction heating with medium frequency current of $2500 \mathrm{~Hz}$ were recommended for extensive application in various branches of industry were obtained from their experience.

Babkib and Sharapov (2011) modeled the strength of the magnetic field of welding current. They obtained calculation expressions for the welding current magnetic field intensity distribution in the welded product and current density in the welding arc. Balaganskii and Ivanaiskii (2011) modeled the process of induction surfacing of components. They described the mathematical model used in the development of the process of surfacing components. There have variable cross-sections for evaluating the productivity and quality of the deposited layer, for obtaining information on the energy requirement from the external power source for the generation of energy in heated components and, consequently, for selecting the controlled parameters of the surfacing process to ensure the optimum values of the output characteristics of the process.

Gruszczyk (2013) presented his investigations on the development of new consumables for welding and weld surfacing of grey cast iron. Arc weld surfacing with tube electrodes, without preheating or heated up to $300{ }^{\circ} \mathrm{C}$, is a method which enables us to obtain sound weld overlays, the structure and properties of which are similar to those of grey cast iron. His method is useful for the repair of small casting defects.

Induction heating has the ability to rapidly heat specific areas of a metal part, such as the teeth of a gear or bearing area of a shaft (Haimbaugh, 2001). Not only superior mechanical properties are produced in such areas, but also the entire part doesn't need to be heated as with furnace treating. The most significant benefits are superior mechanical properties, lower manufacturing costs and manufacturing comparability. The development of highfrequency induction power supplies provided a means of using induction heating for surface hardening (Haimbaugh, 2001). The field in which typical parts induction surface hardening is used include; transportation field (camshafts, axle shafts, transmission shafts, crankshafts, universal joints, gears, wheel spindles, ball studs, and valve seats), machinetool field (lathe beds, transmission gears, machine beds, and shafts), metalworking and hand-tool fields such as hammers, rolling-mill, armature shafts, diagonal pliers, and so forth (Haimbaugh, 2001). In our study, the high frequency induction system was used for welding of the PM compacts.

This paper presents an example of the ultra high frequency induction welding process in powder metal compacts at 180 seconds heating and 80 seconds cooling.

\section{MATERIALS AND METHODS}

\subsection{Metal powder and preparation of the powders}

In this study ASC100.29 powders were used for the powder metal compacts. These powders were produced by the Hougenes Co. The powder size range was $45-106 \mu \mathrm{m}$. The powders were mixed for 20 minutes at $25 \mathrm{rpm}$ in a V-type mixer to produce a homogeneous mixture. The mixed powders were compacted by using uniaxial cold pressing at $600 \mathrm{MPa}$. These iron based PM compositions are used in the automotive industry. The powder metal sample sizes were $10 \times 10 \times 55 \mathrm{~mm}$ and weighed around 37 grams.

\subsection{Sintering processes}

PM compacts were sintered by the conventional method (with electric resistance furnace) for $30 \mathrm{~min}$ utes at $1120{ }^{\circ} \mathrm{C}$ under $10 \% \mathrm{H}_{2}, 90 \% \mathrm{~N}_{2}$ static atmosphere to protect samples from the negative effect of air. Compacts were cooled naturally.

\subsection{Welding process}

In this study; a horizontal coil was used for this welding process. The coil was designed for the induction welding process of PM compacts. 

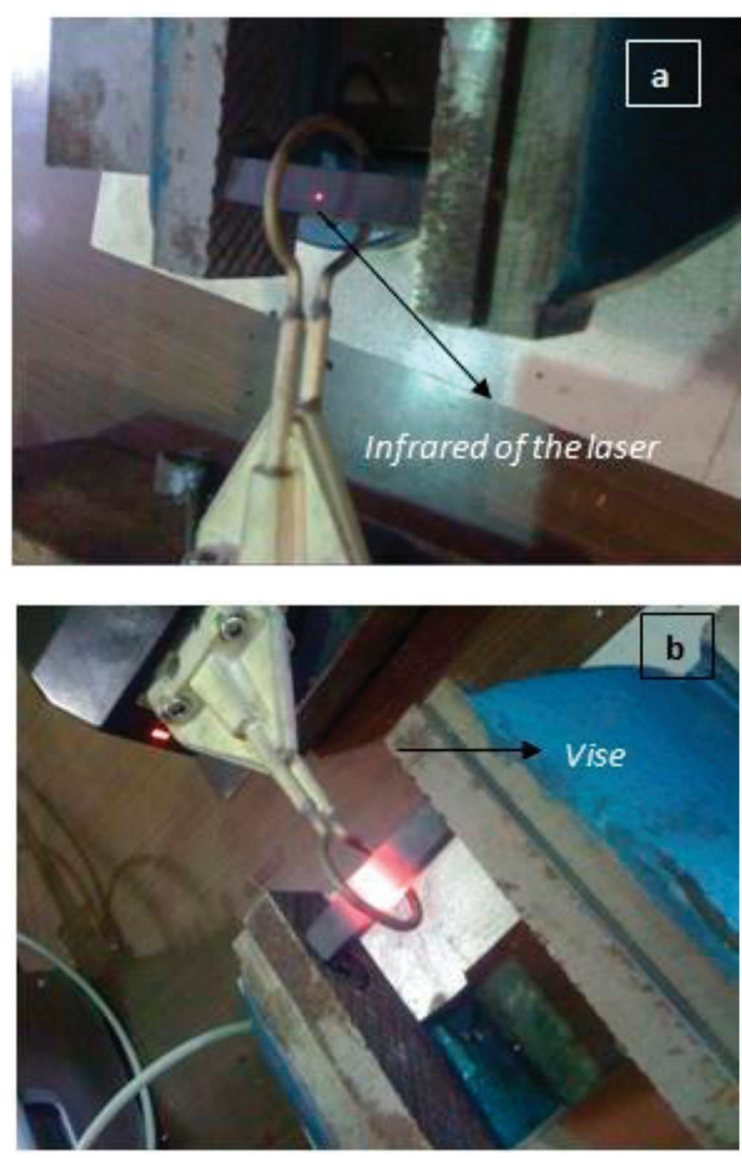

FIGURE 1. UHFIW process: a) Before, b) During.

Diameter of $4 \mathrm{~mm}$ and a wall thickness of $0.5 \mathrm{~mm}$ were used. The copper wire was wrapped one making a coil with an inner diameter of $20 \mathrm{~mm}$. Magnetic flux was achieved homogenously by centering the PM compact. Firstly, PM compacts were cut into two parts, and then they were welded with the induction system. Ten compacts were used for five welding process. All compacts were welded by $2.5 \mathrm{~kW}, 900 \mathrm{kHz}$ (high frequency) induction system for 3 minutes under atmospheric environment. The temperature of the compacts was measured by an infrared thermometer $\left( \pm 5^{\circ} \mathrm{C}\right)$. The welding temperature was measured and fixed by the infrared laser of the induction system. The infrared laser powered by the induction generator. PM compacts were clamped using a vise. The induction coil was fastened during the welding repairing the compact. The welding system and how the compacts were clamped in the vise is shown in Figure 1a and the welding process is shown in Figure 1b.

The heating, welding and cooling durations of the in heat cycle of the UHFIW is given in Figure 2. At the Curie temperature, heating was fixed for 5 seconds (between the $7^{\text {th }}$ and $12^{\text {th }}$ seconds). PM compacts were cooled naturally.

In the induction welding process, compacts were heated very quickly. Because of the rapid heating and atmospheric environment, some color changes were seen in the PM compacts (Fig. 3). The welding process was carried out under atmospheric environment because we wanted to show how easy this process can be applied in industry.

Magnetic flux that interacts with the sample penetrates to a certain depth. This is defined as "penetration depth" according to the literature (Zinn and Semiatin, 1988). Penetration depth (d, expressed at $\mathrm{mm}$ ) was calculated from the following equation (1):

$$
d=500 \sqrt{\rho / \mu f}
$$

Where $\rho$ is a specific resistivity, $\mu$ is magnetic permeability and $\mathrm{f}$ is frequency. The penetration depth was calculated as $0.7 \mathrm{~mm}$ when a frequency of $900 \mathrm{kHz}$ was used during the experiments.

The processing parameters of conventional sintering and UHFIW of PM compacts are given in Table 1. The sintering and welding stages of both processes are illustrated by the flow chart in Figure 4.

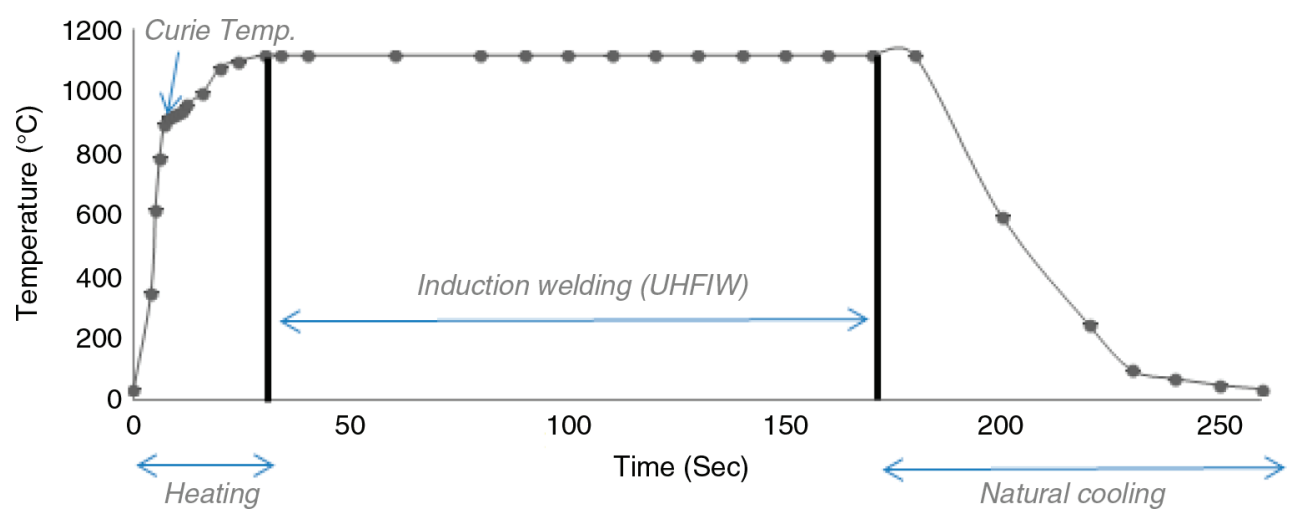

FIGURE 2. The heat cycle of the UHFIW process (Error range: $\pm 5^{\circ} \mathrm{C}$ ). 


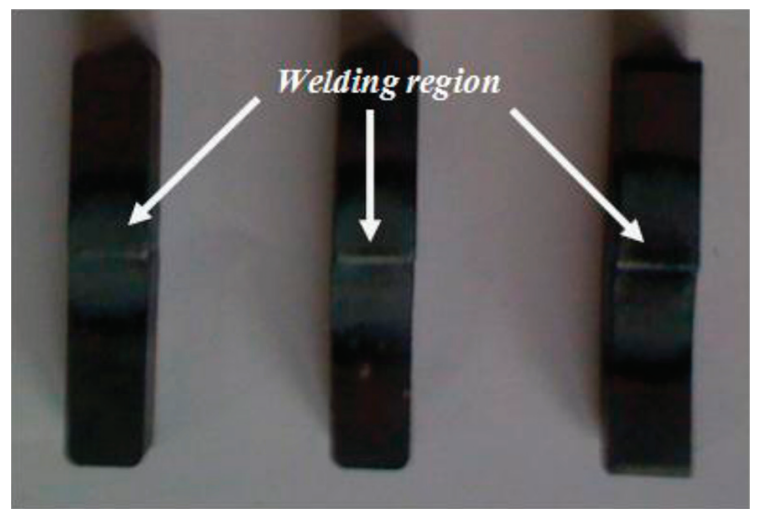

FIGURE 3. Induction welded PM compacts.

\subsection{Characterization methods}

Densities of the sintered samples were measured before welding process using the Archimedes principle. In order to provide a homogenous distribution of magnetic flux on the induction sintered sample, the cross-sections of the samples had to be equal. Therefore, instead of using transverse rupture strength sample according to ASTM standards with dimensions of $6.35 \times 12.7 \times 31.7 \mathrm{~mm}$ (B 528-99), the samples for the Charpy impact tests according to ASTM standards with dimensions of $10 \times 10 \times 55 \mathrm{~mm}$ (E 23-02a) were used. Welded samples were tested to determine the mechanical properties. Five samples were used in the mechanical tests for each parameter. Charpy impact tests were performed to determine impact toughness in longitudinal and transverse direction by using ZBC-1400 impact test machine. Three point bending tests were performed on the samples by using the Autograph Shimadzu AG-IS $100 \mathrm{kN}$ universal test machine. Tensile samples were prepared from welded samples with DIN standard (50125:2009-07 Form E) dimensions by using CNC machine as seen in Figure 5.

Tensile strength and strains were measured by using the Autograph Shimadzu AG-IS 100 kN universal test machine. Macro Brinell Hardness tests were carried out on the surface of welded sample by

TABLE 1. The processing parameters of conventional sintering and ultra high frequency induction welding of PM compacts

\begin{tabular}{lll}
\hline Parameters & $\begin{array}{c}\text { Applied value for } \\
\text { conventional sintering }\end{array}$ & $\begin{array}{c}\text { Applied value } \\
\text { for UHFIW }\end{array}$ \\
\hline Maximum Temperature & $1120^{\circ} \mathrm{C}$ & $1120^{\circ} \mathrm{C}$ \\
Durations & 30 minutes & 3 minutes \\
Heating rates & $\sim 25^{\circ} \mathrm{C} \mathrm{min}^{-1}$ & $\sim 45^{\circ} \mathrm{C} \mathrm{s}^{-1}$ \\
Cooling rates & Naturally & Naturally \\
Environments & $10 \% \mathrm{H}_{2}, 90 \% \mathrm{~N}_{2}$ & Atmosphere \\
\hline
\end{tabular}

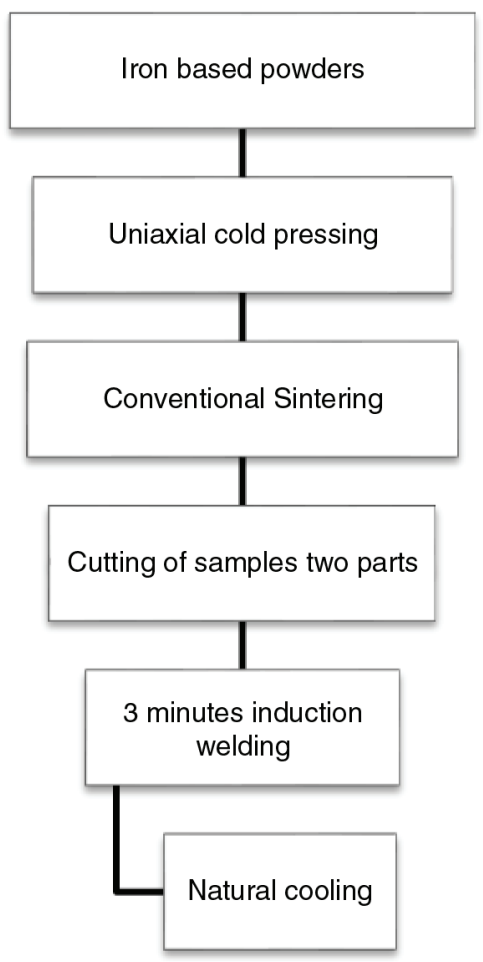

FIGURE 4. Flow chart of all sintering and welding processes.

using MMS 200 RB Macro Brinell Hardness Test equipment with a load of $100 \mathrm{kgf}$. Microstructure images and fracture surfaces images of the samples were observed by using a JEOL JSM-6060 Scanning Electron Microscope.

\section{RESULTS}

Charpy and three point bending tests were applied to the $10 \times 10 \times 55 \mathrm{~mm}$ compacts. With the tensile tests, PM compacts were produced by the CNC machine using the ASTM standards. Hardness measurements were taken from to the surface of the compacts. The measurements points are shown in Figure 6. The distance between each point was $3.36 \mathrm{~mm}$. The HRB hardness results are given in Figure 7.

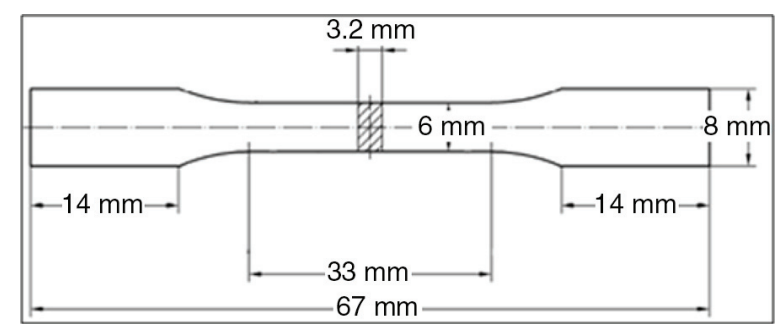

FIGURE 5. Calculated DIN standard dimensions diagram of the tensile test sample. 


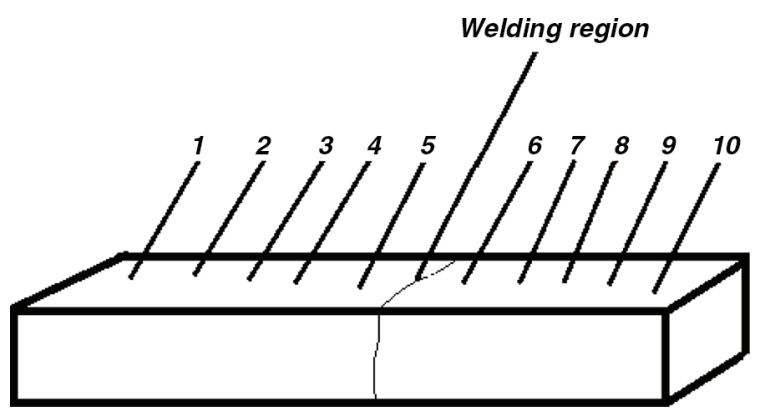

FiguRE 6. Hardness test points of the PM compacts.

Average strength, bending strain \%, tensile strength, Rockwell B (HRB) hardness, Charpy and density values for induction welded compacts are given in Table 2 .

The microstructures of welded and unwelded regions of the 3 minutes welded samples are shown in Figure $8 \mathrm{a}$ and $8 \mathrm{~b}$ respectively. Fracture surfaces images of PM compacts are shown in Figure 9.

\section{DISCUSSIONS}

The HRB hardness results are given in Figure 7 based on the test numbers in Figure 6. It was seen that measurements around the welding region i.e, points 5 and 6 , have the highest HRB hardness values. This is due to the welding process.

In previous works, (Çavdar, 2009; Çavdar and Atik 2009; Çavdar and Atik, 2014a; Çavdar and Atik, 2014b) we compared conventional and induction sintered samples density results. Different PM compositions of pure iron, iron-copper (3wt.\%) and iron-bronze ( $3 \mathrm{wt} . \%$ ) were used in their studies. The highest density results were obtained from induction sintered compacts. Unexpectedly, the density results of the pure iron and iron-bronze PM compacts were similar. The $3 \mathrm{wt} . \%$ copper PM compacts decreased by about in $2 \%$ density compared to the induction sintered compacts. Similar density results were obtained from PM compacts used in this study. Therefore, sintered samples reached nearly $89 \%$ of theoretical density. Our final density results were almost same with the referred by Wu et al., (2012).

The mechanical test results agree with previous works (Cavdar and Atik 2008; Çavdar, 2009; Çavdar and Atik 2009; Çavdar and Atik 2010; Çavdar and Atik 2014). Comparing our results from this study with references listed, the conventional sintered PM compacts' density results (av. $6.78 \mathrm{~g} \mathrm{~cm}^{-3}$ ) and bending strengths (av. $323 \mathrm{~N} \mathrm{~mm}^{-2}$ ) are almost the same. Nevertheless, induction sintered compacts HV hardness results were approximately $4 \%$ higher than the conventional sintered compacts for PM compacts each other. This shows that medium frequency induction sintered compacts' surfaces are less hard. Surface hardening depends upon the frequency of the induction system.

Microstructure images (Fig. 8) were taken from a cross-section of the iron based compact which were gridded, polished and etched $\left(2 \% \mathrm{NH}_{3}, 98 \%\right.$ alcohol). Microstructure images of the three minutes induction welded iron based PM compacts shown respectively: Figure $8 \mathrm{a}$ the welding region of the $\mathrm{PM}$ compact $(\times 200)$ and Figure $8 \mathrm{~b}$ the unwelded region of the PM compact $(\times 200)$.

A gray spot region was observed along the joining line in welding regions of the samples. As observed in

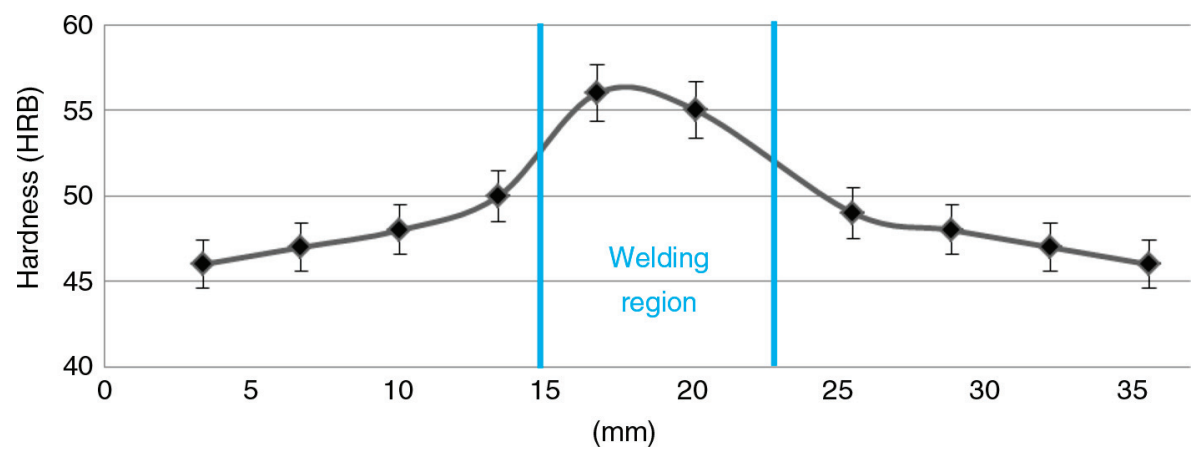

FIGURE 7. Average HV hardness results of three minutes induction welded compacts.

TABLE 2. Average results of the mechanical properties, hardness and densities of the induction welded compacts (Error range: $\pm 3 \%$ )

\begin{tabular}{lcccc}
\hline $\begin{array}{l}\text { Bending Strength } \\
\left(\mathbf{N ~ m m}^{-2}\right)\end{array}$ & $\begin{array}{c}\text { Tensile Strength } \\
\left(\mathbf{N ~ m m}^{-2}\right)\end{array}$ & $\begin{array}{c}\text { Tensile strain } \\
(\%)\end{array}$ & $\begin{array}{c}\text { Charpy } \\
(\mathbf{J})\end{array}$ & $\begin{array}{c}\text { Density } \\
\left(\mathbf{g ~ c m}^{-3}\right)\end{array}$ \\
\hline 311 & 110 & 2.14 & 9 & 6.9 \\
\hline
\end{tabular}



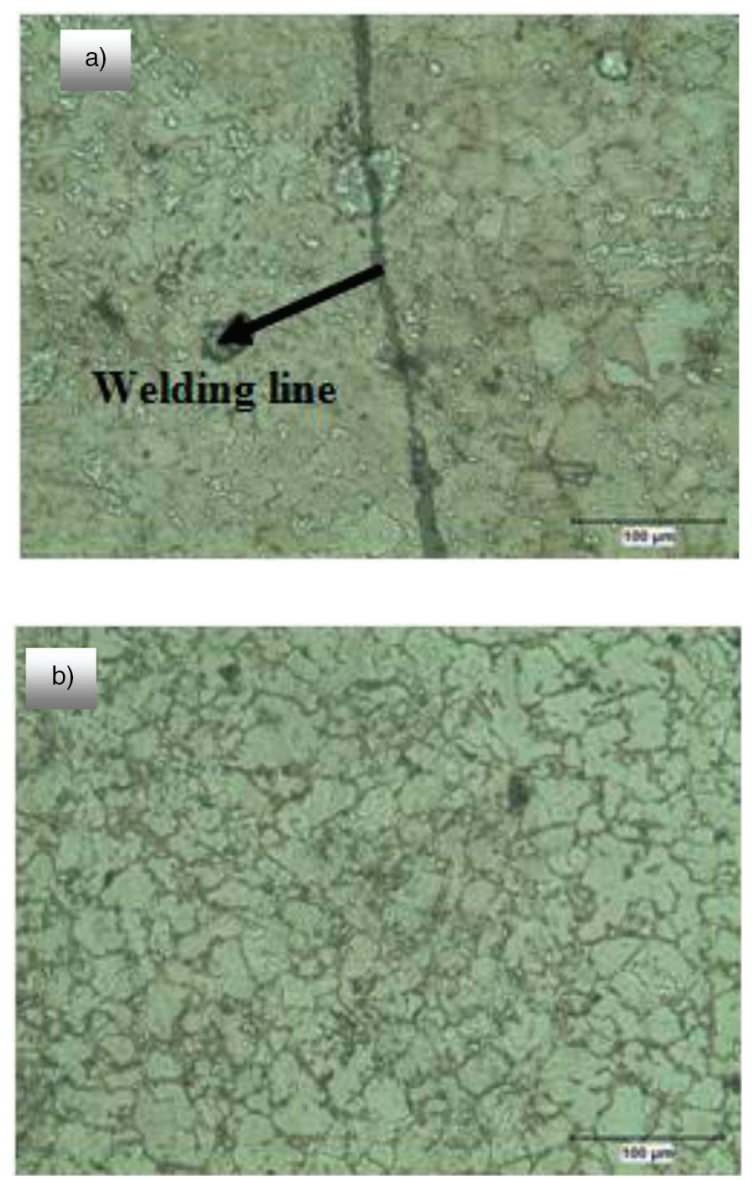

FIGURE 8. Microstructure images of the PM compact: a) Welding region $(\times 200)$, b) Unwelded region $(\times 200)$.

Figure $8 \mathrm{a}$, there is no significant microstructural difference between the left and right sides of the welding line. Comparing the welding regions (Fig. 8a) with the unwelded regions of the samples (Fig. 8b), quite significant grain size differences were identified i.e. grain growth was observed on both sides of the welding line.

In Figure 9, the broken surface of the whole PM compact (a) and microstructure images of this broken surface (b) are shown. The penetration depth of the induction is clearly seen in Figure 9a. This regain of the PM compacts was induction hardened. Thanks to magnetic field of the induction system, this penetration was occurred a depth of approximately $0.7 \mathrm{~mm}$ (from the surface). Due to the induction hardening, this region was broken brittle. The other area of the compact was broken ductile. The ductility of the region, iron powders were severed occurred on the other side of the compact (Fig. 9b). Ductility was a proof of well densification in the sintered samples (Çavdar, 2009). Initiation of neck formation was observed during the induction welding of iron based PM compacts. Also UHFIW method determined that iron based PM compacts were welded more perfectly.

In the induction process, compacts were heated together with magnetic fields and convention transfer. We reported that in the induction sintering process $(30-50 \mathrm{kHz})$, magnetic fields passed through aproximetly $35 \mathrm{~mm}$ from interior and exterior surface of the PM bushing compacts (Çavdar, 2009; Cavdar et al., 2014). Because of these magnetic filelds almost $70 \mathrm{~mm}$ of the PM bushing compacts' cross-section were heated at the same time. This resulted in quicker heating and sintering of the PM compacts. In addition to the induction sintering proccess, magnetic filelds were passed through approximently $0.7 \mathrm{~mm}$ in the induction welding $(900 \mathrm{kHz})$ process too.

The UHFIW method can be useful for the repair of small casting defects. Due to heating the compacts homogenously, induction coils have to be designed for compacts. Otherwise the welding

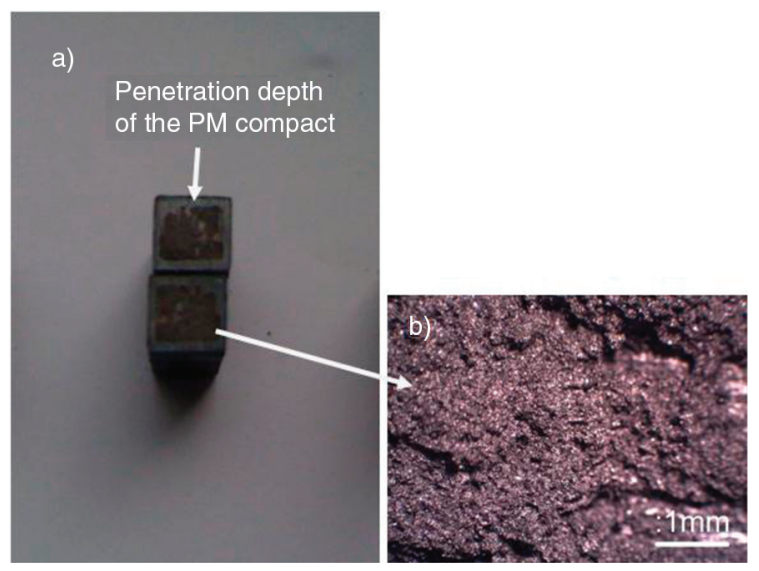

FIGURE 9. a) Broken surface of the PM compact, b) Microstructure image $(\times 20)$.

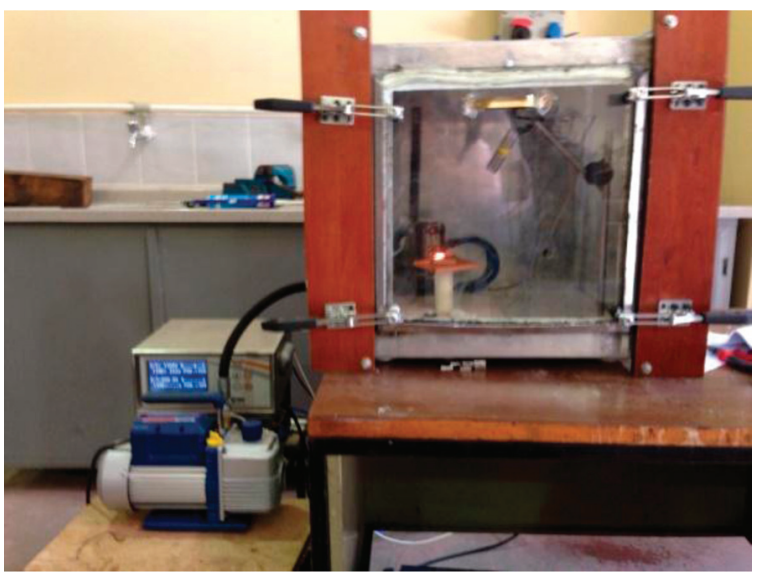

FIGURE 10. UHFIW system in a vacuum box. 
process will not be homogenous. Induction coil design was studied for the medium frequency induction sintering process in my previous work and high frequency induction design was studied for UHFIW.

PM compacts were welded and sintered with the ultra high induction system. This UHFIW process can be used for all materials, but only the heating temperature can be calculated correctly and the welding temperature has to be fixed.

An inert or vacuum atmosphere would improve the surface roughness and structure of the iron compacts. Results are inspired us next research project to investigate vacuum and /or inert atmospheric conditions in the UHFIW system is shown in Figure 10.

\section{CONCLUSIONS}

The following results were obtained:

- Iron based PM compacts were welded successfully with the ultra high frequency induction system.

- There wasn't any weld overlays in the surfaces of the PM compacts (Fig. 3). This is the most important advantage of this technique.

- Because this induction system was used in the welding process, compacts were welded and hardened in the same time.

- The penetration depth was $0.7 \mathrm{~mm}$ when we used an induction generator with a power of $2.8 \mathrm{~kW}$ and frequency of $900 \mathrm{kHz}$. This is the induction hardened depth of the induction welded region.

- It was calculated that, $13.26 \mathrm{~kW} \mathrm{~h}^{-1}$ of energy was needed for induction welding of $1 \mathrm{~kg}$ of PM.

\section{ACKNOWLEDGMENTS}

The research in this paper was supported by Celal Bayar University BAP project (FBE 2012-022).

\section{REFERENCES}

Babkib, A.S., Sharapov, S.N. (2011). Modelling the strength of the magnetic field of welding current. Welding International 25 (4), 301-304. http://dx.doi.org/10.1080/09507116. 2010.540883 .

Balaganskii, A.Y, Ivanaiskii, V.V. (2011). Modeling the process of induction surfacing of components with a variable cross section. Welding International 25 (9), 710-714. http:// dx.doi.org/10.1080/09507116.2011.566746.

Çavdar, U. (2009). Identification parameters for the induction sintered iron based powder metal compacts, $\mathrm{PhD}$ thesis, Celal Bayar University.

Cavdar, U., Atik, E. (2008). Sintering with induction. Euro PM 2008 Conference (3), 33-38.

Çavdar, U., Atik, E. (2009). Induction sintering of $\mathrm{Fe}-2 \mathrm{Cu}$ PM compacts. Euro PM2009 Conference, 13-19.

Çavdar, U., Atik, E. (2010). Induction sintering of \% $3 \mathrm{Cu}$ Contented Iron Based Powder Metal Parts. Modern Applied Science 4 (3), 63-70.

Çavdar, U., Atik, E. (2014a). Investigation of conventional - and induction - sintered iron and iron-based power metal compacts. JOM, Published online. http://dx.doi.org/10.1007/ s11837-014-0977-0.

Çavdar, U., Atik, E. (2014b). Properties of boronized, carbonitrided and steamed iron-based compacts. Materials Testing 56 (2), 126-130. http://dx.doi.org/10.3139/120.110533.

German, R.M. (1994). Powder metallurgy science, 2th Edition, MPIF, USA, pp. 400-403.

German, R.M. (1996). Sintering theory and practice, A Willey INC. USA, 313-362, 373-400, 403-420.

Gruszczyk, A. (2013). New possibilities for welding and surfacing of grey iron. Welding International 27 (12), 915-919. http:// dx.doi.org/10.1080/09507116.2012.708481.

Haimbaugh, R.F. (2001). Practical induction heat treating, ASM International, USA, pp.3-5, 165.

Kuznetsov, M.A., Zernin, E.A. (2012). Nanotechnologies and nanomaterials in welding production. Welding International 26 (4), 23-26. http://dx.doi.org/10.1080/09507116.2 011.606158 .

Riera, M.D., Prado, J.M. (2006). Modelling of the plasticity in cold compaction of metal powders. Rev. Metal. 42 (6), 456-462.

Shulyak, A.A., Startsev, A.V., Korovin, E.M., Korolkov, P.M. (2011). Local heat treatment of large welded pressure vessels by induction heating. Welding International 25 (8), 652-655. http://dx.doi.org/10.1080/09507116.2011.566741.

Wu, M.W., Tsao, L.C., Shu, G.J., Lin, B.H. (2012). The effects of alloying elements and microstructure on the impact toughness of powder metal steels. Mat. Sci. Eng. A 538, 135-144. http://dx.doi.org/10.1016/j.msea.2011.12.113.

Zinn, S., Semiatin, S.L. (1988). Elements of induction heating design, control and applications, EPRI, ASM International, USA, pp. 3, 12-13. 